\title{
Logotipos das Folhas: uma comparação entre Folha da Noite, Folha da Manhã e Folha de S. Paulo ao longo de 100 anos de história dos jornais
}

\author{
Folha's logotypes: a comparison between Folha da Noite, Folha da Manhã, \\ and Folha de S. Paulo along a 100 years of the newspapers' history
}

Diego Manzini Maldonado, Priscila Lena Farias

memória gráfica, design de jornal, identidade visual, tipografia

Este artigo apresenta uma análise comparativa dos logotipos dos jornais Folha da Noite, Folha da Manhã e Folha de S. Paulo, que, em conjunto, completaram cem anos de existência em 2021. A análise foi conduzida observando o contexto histórico, e comparando os estilos gráficos dos logotipos com os de outras publicações e tendências de design, usando como base fichas de análise com ênfase em aspectos tipográficos formais. Gráficos comparativos gerados para cada quesito das fichas permitiram refletir sobre a identidade visual de uma das mais importantes empresas de notícias de São Paulo e assim preencher uma lacuna nos estudos sobre a memória gráfica paulistana.

graphic memory, newspaper design, visual identity, typography

This paper presents a comparative analysis of the logotypes of the newspapers Folha da Noite, Folha da Manhã and Folha de S. Paulo, which, in 2021 completed a hundred years of existence. The analysis was conducted observing the historical context, and comparing the graphic styles of the logotypes with those of other publications and design tendencies, having as a basis analysis sheets emphasising formal typographic aspects. Comparative charts generated for each item in the sheets allowed for a reflection on the visual identity of one of the main São Paulo news media companies, filling a blank in the studies on São Paulo city graphic memory.

\section{Introdução}

Em 19 de fevereiro de 1921, surgiu, em uma São Paulo de 580 mil habitantes, o jornal vespertino Folha da Noite. Não havia, então, bancas de jornal. A Folha da Noite, com oito páginas, era distribuída por gazeteiros, que gritavam manchetes nas calçadas, em busca de atenção da população que passava (Pinto, 2012). Naquele período, o principal jornal matutino era O Estado de S. Paulo (hoje também conhecido como Estadão), mas o Correio Paulistano, jornal editado pelo Partido Republicano Paulista desde o século XIX, que ainda circulava, também era relevante, entre outros.

Segundo Pilagallo (2012), em seu livro História da imprensa paulista, tanto O Estado quanto o Correio eram conhecidos por se dirigir a um público de elite econômica e intelectual. Já

Anais do $10^{\circ} \mathrm{CIDI}$ e $10^{\circ} \mathrm{CONGIC}$

Kelli C.A.S. Smythe, Rafael de Castro Andrade (orgs.)

Sociedade Brasileira de Design da Informação - SBDI

Curitiba | Brasil | 2021
Proceedings of the $10^{\text {th }} \mathrm{CIDI}$ and $10^{\text {th }}$ CONGIC

Kelli C.A.S. Smythe, Rafael de Castro Andrade (orgs.)

Sociedade Brasileira de Design da Informação - SBDI Curitiba | Brazil | 2021 
jornais vespertinos possuíam notícias e linguajar voltados para o pequeno comerciante e o funcionário público (Pilagallo, 2012). O Estado teve por um tempo uma edição vespertina, chamada pela população de Estadinho. Quando este foi descontinuado, jovens jornalistas demitidos pelo Estado criaram a Folha da Noite (Pilagallo, 2012). Olívio Olavo de Olival Costa foi fundador e diretor do jornal até 1930 (Pinto, 2012).

Após o sucesso da Folha da Noite, surgiu, em $1^{\circ}$ de julho de 1925, a Folha da Manhã, que competia no mercado dos jornais matutinos, com linha editorial próxima à de seus concorrentes, como O Estado de S. Paulo, voltada para um público mais elitista (Pilagallo, 2012). Podemos notar que nos primeiros anos o logotipo da Folha da Noite e da Folha da Manhã (Fig. 1) eram bem semelhantes, possivelmente para enfatizar que eram produtos de uma mesma empresa.

Fig. 1: Logotipos de estréia da Folha da Noite (1921) e Folha da Manhã (1925).

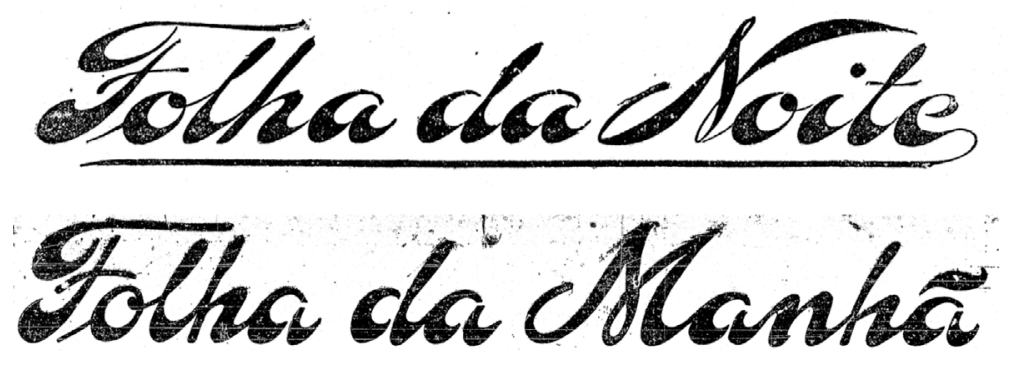

Em 1930, a empresa que publicava as Folhas foi invadida e destruída por ser responsável por periódicos que se opunham ao governo de Getúlio Vargas. Costa perdeu assim todo o seu patrimônio, e vendeu a empresa para Octaviano Alves de Lima. Em 1931 foi então fundada a empresa Folha da Manhã Ltda.

Nos anos 1960, surgiu a Folha de S. Paulo, que uniu ambos os títulos, Folha da Noite e Folha da Manhã, em uma só publicação, matinal. ${ }^{1}$ Em 1962, recém saído do cargo de Secretário da Fazenda, o empresário Octavio Frias de Oliveira assumiu a direção da empresa, cargo que manteve até 1991. Oliveira foi sucedido por seu irmão mais novo, o jornalista Otavio Frias Filho, que dirigiu a Folha de 1984 até 2018 (Pinto, 2012; Folha de S. Paulo, 2018).

A partir do final dos anos 1980, a Folha de S. Paulo iniciou um processo de alterações editoriais. Foi elaborado neste período o Projeto Folha, um conjunto de normas que determinava como os textos do jornal deveriam ser escritos. Como consequência destas alterações, também foi proposta uma reforma gráfica. No início dos anos 1990, a Folha de $S$. Paulo tornou-se o jornal com a maior tiragem do Brasil. Em 1991 possuía mais da metade da publicidade de varejo de São Paulo, e em 14 de agosto de 1994 teve tiragem recorde, de 1,1 milhão de exemplares (Pinto, 2012). Um ano antes, em 1993, a designer carioca Eliane

\footnotetext{
${ }^{1}$ A Folha publicou também, entre 1924 e 1999, o jornal Folha da Tarde. Este, no entanto, apresenta peculiaridades e um caminho diferente dos demais, e por isso não é considerado nas análises apresentadas neste artigo.
} 
Stephan, então editora de arte da Folha de S. Paulo, foi designada para desenvolver um novo projeto gráfico para a Folha de S. Paulo, que incluiu também um novo logotipo.

O desenvolvimento deste logotipo resultou em uma parceria de Stephan com o escritório berlinense Metadesign, fundado pelo tipógrafo alemão Erik Spiekermann. Stephan conheceu Spiekermann, através do livro Stop stealing sheep \& find out how type works (Spiekermann, Ginger, 1993). Quando teve a oportunidade de contratar um escritório internacional para trabalhar em conjunto, Stephan entrou em contato com o tipógrafo (Maldonado, 2019).

Spiekermann já era um designer de tipos experiente e tinha como seu funcionário o holandês Lucas de Groot, na época um iniciante na área. Segundo Stephan e Spiekermann (comunicação pessoal), Lucas De Groot foi quem trabalhou de forma mais ativa neste projeto.

A questão central que este artigo busca responder é: como o logotipo das Folhas evoluiu, graficamente, entre 1921 e 2021?. Para respondê-la, métodos de análise gráfica e tipográfica foram adotados, dentro de uma perspectiva de memória gráfica, chegando aos resultados descritos a seguir.

\section{Métodos e procedimentos}

Os logotipos das Folhas utilizados nas análises apresentadas neste artigo foram retirados de reproduções dos jornais disponíveis no Acervo Folha de forma digital, com acesso livre para assinantes. Referências de outros periódicos e imagens de contexto histórico foram obtidas nos repositórios digitais do Arquivo de Estado de São Paulo, do Acervo Estadão e da Biblioteca Nacional. Informações históricas sobre os jornais foram retiradas da obra Folha, de Ana E. S. Pinto (2012). Detalhes sobre o projeto gráfico foram obtidos através de entrevista com Eliane Stephan (2019), publicada no podcast Entreletras \#13. Termos utilizados para preenchimento das fichas de análise dos logotipos das Folhas seguem nomenclatura descrita em Farias (2016).

A partir de uma observação de todos os logotipos (Fig. 2), foram levantados pontos-chave que pudessem servir de base para comparações. Os logotipos selecionados cobrem o período em que o jornal se chamou Folha da Noite (a partir de 1921), Folha da Manhã (a partir de 1925) e a junção de ambos os títulos na Folha de S. Paulo, em 1960 (Pinto, 2012).

A análise principal teve como foco a primeira parte dos logotipos, na qual aparecem, em todos, a palavra 'Folha' e as preposições 'da' ou 'de' (Fig. 3). Os complementos 'Noite', 'Manhã' e 'S. Paulo', não foram ignorados, mas detalhes acerca deles foram tratados como informações complementares. 
Fig. 2: Logotipos analisados, divididos em colunas por título, e em ordem cronológica, de cima para baixo.



01/01/1960

FOLHA DE S. PAULO

25/09/1966

FOLHA DE S. PAULO

22/12/1973

FOLHA DE S. PAULO

04/03/1990

FOLHA DE S.PAULO

03/03/1996

FOLHA DE S.PAULO

27/03/2020

FOLHA DE S.PAULO

$07 / 12 / 1940$

$12 / 04 / 1942$

OLHA DA MANHA

FOLHA DA MANHÁ

22/08/1951

FOLHA DA MANHÃ

08/01/1959

FOLHA DA MANHĀ 
A partir dos pontos-chave observados, desenvolveu-se um sistema de fichas de análise, para descrição e comparação dos logotipos (Fig. 4). As fichas foram divididas em quatro categorias principais (dados gerais, estilo tipográfico, anatomia tipográfica e layout), cada uma com suas subdivisões:

1. Dados gerais

- Imagem do logotipo: arquivo com reprodução do logotipo;

- Autor(es): designers do logotipo;

- Data do primeiro uso;

- Data do último uso;

- Fonte da imagem;

- Similaridades: relação com o design de outros logotipos, contemporâneos ou não;

- Diretor do jornal: ocupante do cargo no momento em que o logotipo estreou;

- Chefe de redação: ocupante do cargo no momento em que o logotipo estreou;

- Extras: outras informações

2. Estilo tipográfico

- Classificação: classe do sistema BS 2961 (Farias, 2016);

- Peso: leve, regular, negrito, ou pesado;

- Postura: vertical, ou inclinada;

- Largura: comprimida, condensado, regular, estendida, ou variável;

- Caixa: alta, baixa, e/ou versaletes;

- Espacejamento: justo, ou solto;

- Contraste: alto, médio, baixo, ou sem contraste;

- Eixo de contraste: vertical, diagonal, ou invertido;

- Extras: outras informações.

3. Anatomia tipográfica

- Estilo da serifa: quadrada, triangular, romana, ou romana triangular;

- Topo do A: reto, agudo, serifa dupla, serifa esquerda, ou não se aplica (minúscula);

- Altura da barra do A: baixa, média baixa, média, média alta, alta, ou não se aplica (minúscula);

- Altura da barra do H: baixa, média baixa, média, média alta, alta, ou não se aplica (minúscula);

- Altura da barra do F: baixa, média baixa, média, média alta, ou alta;

- Terminal superior do F: sem serifa, serifa triangular, ou serifa reta;

- Ornamento;

- Extras: outras informações. 


\section{Layout}

- Posição na página: localização (ex: topo ou variável);

- Contorno: presença de linha de contorno no logotipo;

- Formato da página: tamanho da folha impressa;

- Extras: outras informações.

Fig. 4: Exemplo de ficha de análise de logotipo.

\begin{tabular}{|c|c|c|}
\hline & cód. & fsp@4 \\
\hline & Imagem & \\
\hline & autor(es) & desconhecido \\
\hline & data de $1^{\circ}$ uso & ๑4/๑3/199० \\
\hline & data de último uso & $02 / 04 / 1996$ \\
\hline & referência & Acervo Folha \\
\hline & similaridades & \\
\hline & diretor do jornal & Otavio Frias Filho \\
\hline & chefe de redação & \\
\hline & extras & \\
\hline Estilo tipográfico & & \\
\hline & Classificação & didônica \\
\hline & Peso & negrito \\
\hline & Postura & vertical \\
\hline & Largura & regular \\
\hline & Caixa & alta \\
\hline & Espacejamento & justo \\
\hline & contraste & alto \\
\hline & eixo de contraste & vertical \\
\hline & extras & - \\
\hline Anatomia tipográfica & & \\
\hline & Estilo Serifa & transicional \\
\hline & Topo do A & reto \\
\hline & Alt. barra do $\mathrm{A}$ & média \\
\hline & Alt. Barra do $\mathrm{H}$ & média \\
\hline & Alt. Barra do F & média \\
\hline & Terminal do $\mathrm{F}$ & serifa diagonal única \\
\hline & ornamento & não \\
\hline & extras & - \\
\hline Layout & & \\
\hline & posição na página & topo \\
\hline & Contorno & - \\
\hline & formato da página & Standard $(432 \mathrm{~mm} \times 540 \mathrm{~mm})$ \\
\hline & extras & - \\
\hline
\end{tabular}


Os dados coletados nas categorias Estilo tipográfico, Anatomia tipográfica e Layout através das fichas foram usados para verificar os estilos gráficos mais utilizados pela Folha. A análise foi feita baseada em cada subtópico e em relação ao jornal no qual o logotipo foi publicado.

\section{Resultados}

Nos anos 1920, O Estado de S.Paulo possuía um logotipo similar ao que ainda é usado em 2021, algo que demonstra apego à tradição e busca por consolidação da marca através da repetição. A Folha da Noite estreou com um logotipo bem diferente daqueles d'O Estado e do Correio. No lugar das letras maiúsculas condensadas, grotescas ou serifadas usadas por seus concorrentes, a Folha da Noite apresentava um letreiro simulando escrita feita à mão com pena de bico e alto contraste (Fig. 5).

Fig. 5: Logotipos Folha da Noite, O Estado de S. Paulo e Correio Paulistano em 1921.

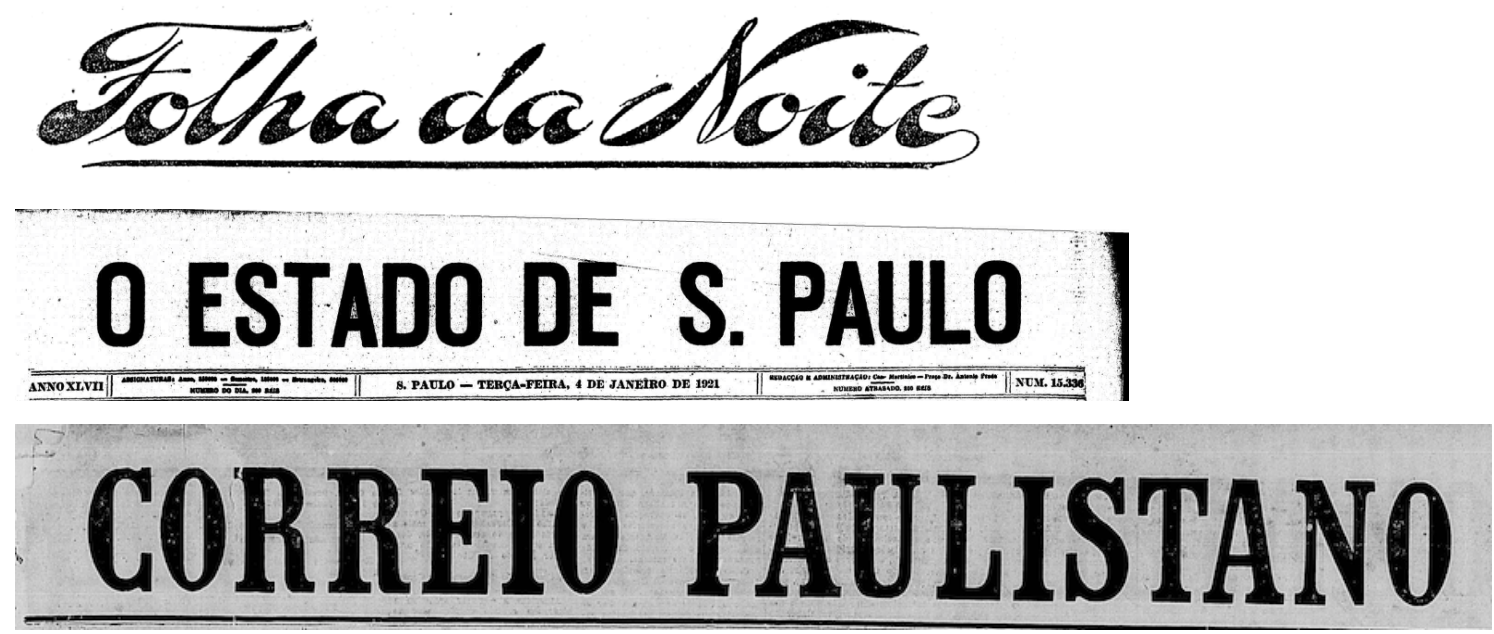

A revista A Cigarra (1914 - 1975), publicada em São Paulo no final dos anos 1910, possuía logotipo com traços que, assim como os da Folha da Noite, poderiam ser classificados como Art Nouveau. É possível, ainda, traçar um paralelo entre o logotipo da Folha da Noite e o da Coca-Cola, que nos anos 1920 tinha aparência similar (Fig. 6), apesar da marca ter chegado oficialmente no Brasil apenas em 1941 (Coca-Cola, 2021).

Fig. 6: Logotipo da revista A Cigarra em edição de 1918, e anúncio da Coca-Cola de 1921 (The Yearround Drink). Fonte: Arquivo do Estado de São Paulo e Coca-Cola (n/d).
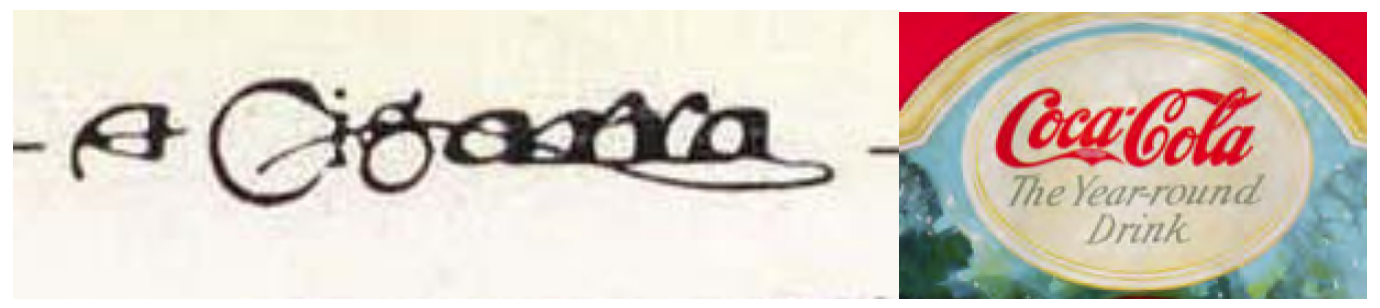
Ao longo de trinta anos de existência, a Folha da Noite adotou 18 logotipos com evidentes variações entre eles (Fig.2, coluna esquerda). Nos anos 1940, chegou a "voltar atrás" e recuperou um design anterior (Fig. 7). É plausível cogitar que esta alteração frequente tenha relação com sua linha editorial mais popular, que buscava o contemporâneo, sem preocupação com a tradição da marca, como o O Estado de S. Paulo aparenta querer firmar.

Fig. 7: Da esquerda para a direita, logotipos de dezembro de 1940, setembro de 1941 e outubro de 1946.

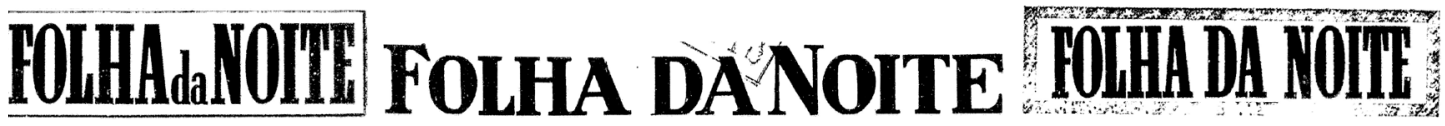

Os logotipos da Folha da Noite entre os anos 1930 e 1940 usavam letras geométricas, típicas do Art Decó, em um momento no qual este estilo se estabelecia em São Paulo, manifestando-se no design e na arquitetura, entre outros. Letras que seguem este mesmo estilo podem ser vistas no jornal A Platéa, no periódico O Malho e em edifícios da época, como o Banco de São Paulo (1938), como mostra a figura $8 .^{2}$

Fig 8: À esquerda, logotipos da Folha da Noite entre 1933 e 1940, à direita, logotipos do jornal A Platéa, do periódico O Malho e detalhe da fachada do Banco de São Paulo.

\section{FOLHA DA NOITE OLHADANOITE OOHADANOITE}
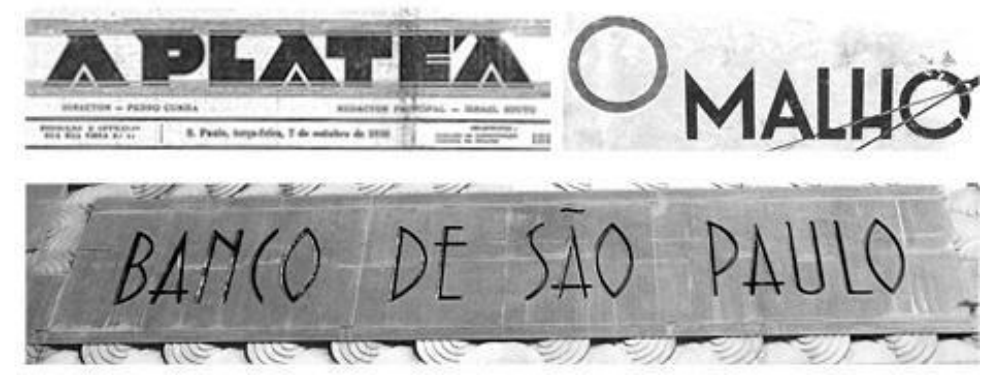

A Folha da Noite alterou seu logotipo onze vezes entre 1933 e 1951, adotando estilos sem serifa, super condensados e serifados, com alto e baixo contraste. No mesmo período, a Folha da Manhã passou por cinco alterações, mais sutis, alterando condensação e detalhes nas serifas de letras como o "A" (Fig. 9).

\footnotetext{
${ }^{2}$ Mais referências de tipografia arquitetônica podem ser encontradas em D'Elboux 2013.
} 
Fig. 9: À esquerda, os logotipos da Folha da Noite em ordem cronológica, por colunas, e à direita os da Folha da Manhã, entre 1933 e 1951.

\begin{tabular}{|c|c|}
\hline \multirow[t]{12}{*}{1933} & FOLHA DANOITE \\
\hline & FOLHADANOITE \\
\hline & FOLHADANOITE \\
\hline & FOLHAdaNOITE \\
\hline & APOLHAdaOOTIE \\
\hline & FOLHA DANOITE \\
\hline & OULADAIOIT \\
\hline & FOLIADA NOIT \\
\hline &  \\
\hline & nome \\
\hline & FOIHA \\
\hline & NolTE \\
\hline & FOLHA da NOITE \\
\hline
\end{tabular}

FOLHA DA MANHÁ

FOLHA DA MANHÃ

FOLHA DA MANHÃ

FOLHA DA MANHÃ

FOLHA DA MANH $\tilde{A}$

Entre 1951 e 1959, últimos anos de ambos os jornais, houveram mais três mudanças no logotipo da Folha da Noite, tanto com diferenças radicais entre estilos (presença de serifas e contraste nos traços), quanto na condensação e uso de caixa baixa ou apenas caixa alta. $\mathrm{Na}$ Folha da Manhã as alterações foram, novamente, mais sutis, afetando o espaçamento entre letras e a proporção entre altura e largura dos caracteres. As últimas versões, que entram em vigor simultaneamente em 01/10/1959, aproximaram-se do design do primeiro logotipo da Folha de S. Paulo, com letras serifadas de perfil semelhante e com proporção, contraste, e espaçamento entre letras bastante similares (Fig.10).

Fig. 10: No topo, os logotipos da Folha da Noite e Folha da Manhã entre 1951 e 1959; abaixo, o logotipo da Folha de S. Paulo em 1960.

\section{1 $\mid$\begin{tabular}{l|l} 
FOLHA da NOITE & FOLHA DA MANHÃ
\end{tabular} FDLHADAMOIT: FOLHA DA WONE ${ }_{1959}$ FOLHA DA NOITE FOLHA DE S. PAULO}


O logotipo da Folha de S. Paulo foi alterado seis vezes entre 1960 e 1996, mantendo-se, a partir de então, praticamente idêntico até 2021. Uma notável alteração do logotipo ocorreu em 1966, dois anos após a compra da empresa Folha da Manhã Ltda. por Octavio Frias de Oliveira. Com ela, o nome do jornal ganhou destaque na página (Fig. 11), chamando mais a atenção nas bancas de jornal.

Fig. 11: À esquerda, a primeira edição da Folha de São Paulo, de janeiro de 1960; e, à direita, capa do mesmo jornal em setembro de 1966.


É possível observar neste logotipo de 1966 alguma relação com o de 1996, desenvolvido por Eliane Stephan e a Metadesign. A estrutura e forma das letras são similares, algo que pode ser observado na proporção dos caracteres, na forma das serifas e terminais, e na altura da barra das letras F, H, E e A (Fig. 12).

Fig. 12: Logotipos da Folha de S. Paulo em 1966 (acima), e 1997 (abaixo).

\section{FOLHA DE S.PAULO FOLHA DE S.PAULO}


Ao comparar o logotipo atual da Folha de S. Paulo com seu principal concorrente, O Estado de S. Paulo, é clara a diferença entre os dois. O Estadão mantém seu logotipo similar ao de 1920, com um tipo sem serifa e sem contraste, enquanto a Folha de S. Paulo traz letras com contraste e serifas, remetendo a formas adotadas pela empresa na década de 1950. (Fig. 13).

Fig. 13: Logotipos do Estado de S. Paulo e da Folha de S. Paulo encontrados nas capas dos jornais em sua edição de 28 de dezembro de 2020.

\section{OESTADO DE S. PAULO FOLHA DE S.PAULO}

Para criar a nova versão do logotipo da Folha de S. Paulo, em 1993, os designers Eliane Stephan, Erik Spiekermann e Lucas De Groot revisitaram todos os logotipos já utilizados nos jornais editados pela empresa Folha da Manhã, buscando por características em comum (Maldonado, 2019).

Ao observar os 36 logotipos da Folha da Manhã, Folha da Noite e Folha de S. Paulo coletados durante a pesquisa aqui relatada, foi possível identificar similaridades entre eles. $\mathrm{O}$ topo do A com terminação reta, por exemplo, aparece nos logotipos dos três jornais. Um H similar em condensação, contraste e peso também aparece nos três jornais, e o S com serifa apenas para dentro aparece tanto no logotipo atual da Folha de $S$. Paulo quanto no anterior, de 1990 (Fig. 14).

Fig. 14: Comparação entre logotipos das três Folhas: (1) Topo do A reto; (2) similaridade na letra H; (3) condensação das letras afetando a largura do logotipo; (4) serifas do S.

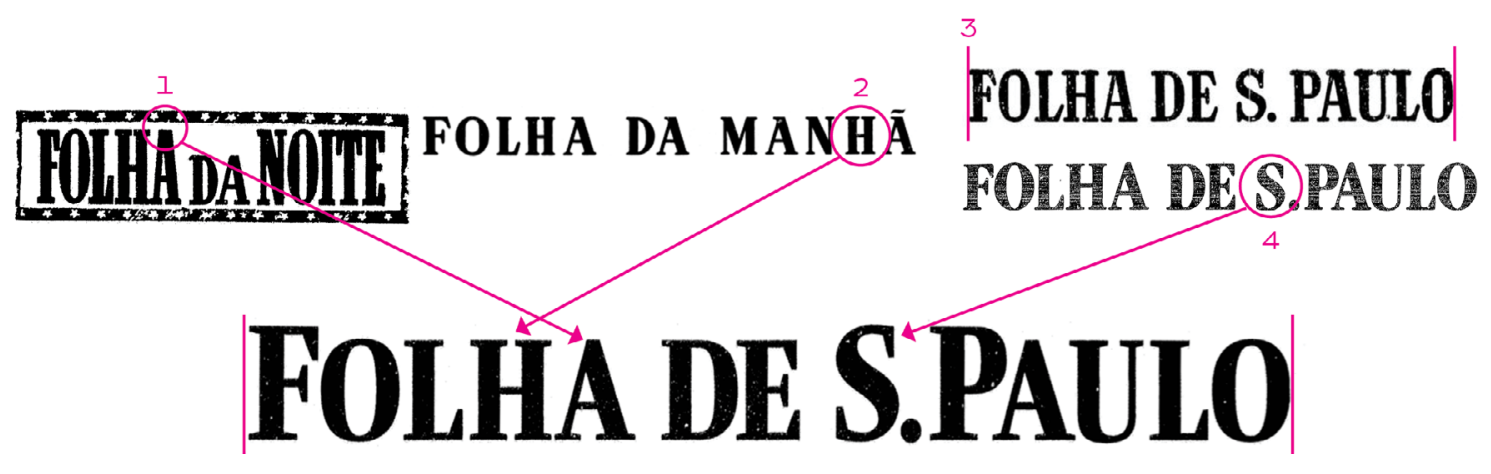

Entre 1996 e 2021, a Folha de S. Paulo não alterou o desenho das letras de seu logotipo, mas um sutil ajuste de espaçamento foi realizado em 1997 (Fig. 15). O logotipo criado em 1993 deu origem à família tipográfica proprietária Folha Serif, de 1994, desenvolvida por Lucas De Groot sob direção de Spiekermann e Stephan, publicada pela primeira vez em 1996 (Folha de S. Paulo, 1996). Esta família tipográfica inspirada no logotipo passou a ser utilizada nos títulos das matérias 
do jornal. A família tipográfica cresceu ao longo do tempo, mas manteve seu conceito original. Assim, podemos dizer que o logotipo definiu uma completa identidade visual para o jornal.

Fig. 15: Sobreposição de logotipos da Folha de S. Paulo de 1996 (em azul) e 1997 (em magenta).

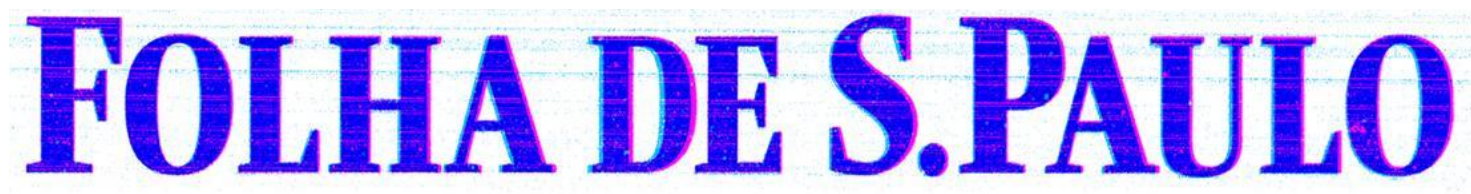

Dados quantitativos sobre os logotipos levantados por meio das fichas de análise podem ser comparados através de gráficos. A figura 16, por exemplo, mostra que os logotipos da Folha da Noite transitaram por múltiplos estilos de letra, enquanto os da Folha da Manhã e da Folha de S. Paulo, concentraram-se sobretudo em didônicas (letras serifadas com alto contraste e serifas filiformes).

Fig. 16: Gráfico de comparação do subtópico 'classificação'. Em azul a Folha da Noite, verde Folha da Manhã e rosa a Folha de S. Paulo. Valores em porcentagem.

\section{Classificações}

80

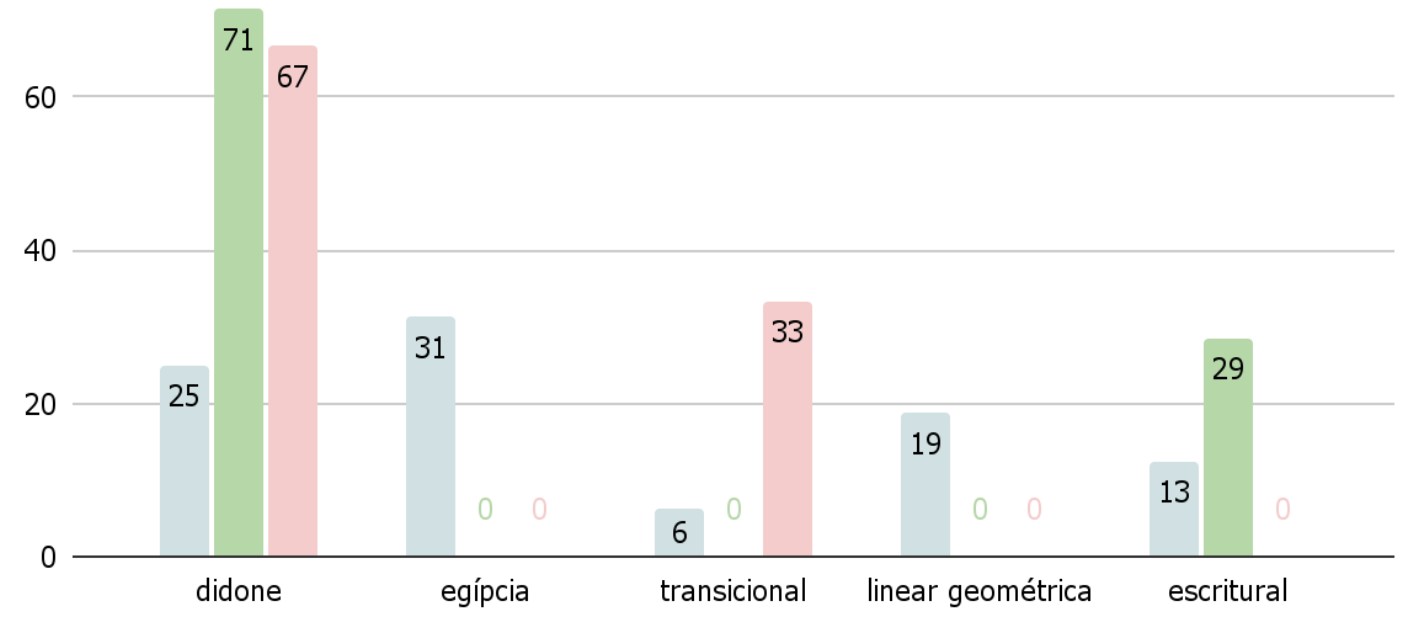

Considerando os subtópicos da ficha temos, como características mais recorrentes, entre 1921 e 2021:

1. Estilo tipográfico

- Classificação: didônicas, 19 logotipos;

- Peso: negrito, 28 logotipos;

- Postura: vertical, 30 logotipos;

- Largura: condensada, 13 logotipos; 
- Caixa: alta, 19 logotipos;

- Espacejamento: justo, 34 logotipos;

- Contraste: alto, 21 logotipos;

- Eixo de contraste: vertical, 28 logotipos.

2. Anatomia tipográfica

- Estilo Serifa: quadrada, 14 logotipos;

- Topo do A: reto, 11 logotipos;

- Alt. barra do A: média, 16 logotipos;

- Alt. Barra do H: média, 26 logotipos;

- Alt. Barra do F: média, 19 logotipos;

- Terminal do F: serifa triangular, 15 logotipos.

3. Estilo tipográfico

- Posição na página: topo, 24 logotipos.

\section{Considerações finais}

O exame dos dados coletados permitiu verificar uma ampla variação nos logotipos da Folha da Noite, algo que não ocorreu em outros títulos publicados pela mesma empresa (Folha da Manhã e Folha de S. Paulo). Isso possivelmente se deu por conta de sua linha editorial, que, diferentemente da Folha da Manhã e Folha de S. Paulo, favorecia o acompanhamento de novos estilos de letra relacionados a seu tempo, em detrimento de uma aposta na memorização da marca pela repetição.

Tendo como parâmetro O Estado de S. Paulo como jornal matinal tradicional e consolidado (Pilagallo, 2012), verificou-se que a Folha da Manhã, assim como seu concorrente, trocou poucas vezes o estilo de seu logotipo. Ao longo de cem anos, as Folhas sempre adotaram logotipos formalmente distintos daquele d'O Estado de S. Paulo, preferindo formas escriturais, geométricas ou serifadas. Um aspecto formal recorrente nos logotipos do Correio Paulistano e O Estado de $S$. Paulo que as Folhas paulistanas também adotaram em meados da década de 1960 é a proporção condensada entre altura e largura dos caracteres.

A evolução dos logotipos das Folhas, examinada a partir de descrição sistemática e da comparação com tendências gráficas nacionais e internacionais permitiu observar o posicionamento destes jornais paulistanos ao longo de sua história. Dados sobre o logotipo de 1996, levantados através de entrevista com a designer responsável por ele, puderam ser verificados através de observação direta. As fichas de análise foram essenciais para tratar e comparar dados referentes a um grande número de logotipos. Os métodos utilizados para se chegar a esta contribuição para os estudos sobre a memória gráfica paulistana podem ser aplicados em outras investigações. 
A pesquisa aqui relatada limitou-se, no que se refere a análises detalhadas, aos logotipos das Folhas. Em investigações futuras, seria interessante poder examinar mais detalhadamente um número maior de periódicos publicados dentro do mesmo recorte temporal em diferentes regiões.

\section{Agradecimento}

A Marcos da Costa Braga por seus comentários a respeito de uma versão anterior deste texto.

\section{Referências}

Coca-Cola. (n.d.). 125 years of Inspiration. Disponivel em: <https://www.cocacolacompany.com/content/dam/journey/us/en/our-company/history/coca-cola-a-short-history125-years-booklet.pdf>

Coca-Cola Brasil (2016). Linha do tempo: conheça a história da Coca-Cola Brasil. Coca-Cola Journey. Disponível em <https://www.cocacolabrasil.com.br/sobre-a-coca-cola-brasil/ahistoria-da-coca-cola-brasil> Acesso em 29/4/2021.

D'Elboux, J. R. (2013). Tipografia como elemento arquitetônico no Art Déco paulistano: uma investigação acerca do papel da tipografia como elemento ornamental e comunicativo na arquitetura da cidade de São Paulo entre os anos de 1928 a 1954. Tese de doutorado, Universidade de São Paulo. Disponível em: <https://teses.usp.br/teses/disponiveis/16/16134/tde-10092013-093443/pt-br.php>

Maldonado, D. M. (Entrevistador). (2019, out 28). Entreletras \#13: Eliane Stephan e as coincidências da vida (No. 13) [Episódio de podcast]. Em: Visual+mente. Visual+mente. Disponível em: https://player.captivate.fm/episode/9b03d773-a6f3-4830-bf24-a40e5a06e6c3

Farias, P. L. (2016). Estudos sobre tipografia: letras, memória gráfica e paisagens tipográficas em Design. Tese de Livre Docência, Universidade de São Paulo, São Paulo. Disponível em <http://www.teses.usp.br/teses/disponiveis/livredocencia/16/tde-10032017-161946/>. Acesso em 20/04/2020.

Folha de S. Paulo. (n.d.) Acervo Folha. Disponível em: <https://acervo.folha.com.br/>.

Folha de S. Paulo. (2018). Morre aos 61 Otavio Frias Filho, diretor de Redação da Folha. Acesso em: 20/4/2021. Disponível em: <https://www1.folha.uol.com.br/poder/2018/08/morreaos-61-otavio-frias-filho-diretor-de-redacao-da-folha.shtml>

Folha de S. Paulo. Novafolha (1996). Folha de S. Paulo, 25/02/1996 n. Especial, 1-12.

Folha de S. Paulo. Novíssima (2010). Folha de S. Paulo, 23/05/2010 n. Especial, 10-11.

Pilagallo, O. (2012). História da imprensa paulista: jornalismo e poder de D. Pedro a Dilma. São Paulo: Três Estrelas.

Pinto, A. (2012). Folha. São Paulo, SP: Publifolha. (Folha explica. Jornalismo).

Spiekermann, E., Ginger, E. M. (1993). Stop stealing sheep \& find out how type works.

Mountain View: Adobe Press. 


\section{Sobre os autores}

Diego Manzini Maldonado, Ba., PPG Design, FAU USP, Brasil <diegomaldonado@usp.br>

Priscila Lena Farias, Dra., PPG Design, FAU USP, Brasil <prifarias@usp.br> 